\title{
2 Local people's perspectives on action learning
}

\author{
Impressions from the Amazon
}

\author{
James Johnson and Benno Pokorny
}

\section{Contextualization}

With the initial aim to consider more adequately the needs, views, and capacities of local resource users, from 2005 to 2009, a consortium of nine universities and non-governmental organizations (NGOs) from Europe and Latin America implemented the EU-funded research and development project, "Forest management by smallholders in the Amazon - An opportunity to enhance forest ecosystem stability and rural livelihood" (ForLive; Pokorny 2013). The project, in partnership with governmental organizations, NGOs, and other relevant actors, analysed promising tree and forest management initiatives of local resource users in the Bolivian, Brazilian, Ecuadorian, and Peruvian Amazon. The purposes were to elaborate locally viable forest use options contributing to local livelihoods and the ecological stabilization of landscapes and define possibilities to promote them as a basis for sustainable local development of the Amazon and beyond. The project focussed on five study areas representing typical agricultural frontier contexts. It described nearly 150 initiatives indicated as promising by experts from governmental agencies and NGOs, as well as representatives from local resource user groups. The initiatives analysed showed great heterogeneity, with cases located in both recent and older frontiers, involving Indigenous people, traditional communities, and settlers. Some locals had small farms with forest areas of less than 5 ha; most holdings were between 50 and 100 ha, and others had access to collectively owned forests of up to several thousand hectares. More than $80 \%$ of the initiatives analysed received external support from governmental or non-governmental organizations for sustainable management of natural forests, plantations, and agroforestry systems for the production of timber, but also NTFPs such as fruits and fibres.

Seventeen initiatives were selected for in-depth analysis. In these case studies, beyond doing conventional academic research, the project invested in transdisciplinary learning. This particularly included an action research and learning component that stimulated and accompanied families and communities in doing their own research on topics defined by them. This component principally sought to establish routines for local learning structured in a sequence 
of learning loops of planning, action, and reflection (Pokorny, Cayres, and Nunes 2005). Followed by an initial phase of informing and mobilizing community members, interested persons were invited to discuss needs and options for local development. Then, the locals decided on the most relevant options and formed local research groups. To achieve their goals, the groups regularly set up short-term plans that defined activities and responsibilities following the specific possibilities and interests of the group members.

In each case study, the project's field assistants facilitated the local research groups; most importantly, they supported the reflection meetings to discuss the group's performance and to define and adjust new work plans to be implemented in the upcoming learning loop. Field assistants were $\mathrm{PhD}, \mathrm{MSc}, \mathrm{BSc}$ students, and NGO employees, who, besides working or assisting the academic project agenda, dedicated up to $50 \%$ of their working time to serving the local research groups. The field assistants were intensively prepared in training workshops held by senior researchers with considerable experience in action and collaborative research, who also supervised the activities in the field including bi-annual personal meetings. Also, a field manual was prepared to explain the working approach and its conceptual underpinnings.

Most local research groups decided to invest in exploring technical questions such as the control of pests and diseases, management of specific crops or trees, and control of fire; others were concerned with markets, particularly those for timber; in some sites, issues related to community organization also played a role. Despite severe challenges for both sides, the local researchers and the field assistants, many of the groups managed to generate valuable and locally relevant findings, and, most importantly, contributed to collective action and improved self-governance of community organizations.

In its final phase, the project invested in a profound reflection on the experiences of all local researchers and field assistants. Reflection included semistructured face-to-face interviews and focus group discussions about the most positive and negative experiences, achievements, and problems and on factors that motivate or demotivate, as well as the interests in and possibility for post-project continuation. Interviews and group meetings were documented - partly recorded and transcribed - and analysed in three steps. First, a small researcher team systematically reviewed the documentation to crystallize the essential statements on the above-mentioned aspects. The outcomes were then presented, discussed, and if necessary corrected and complemented at national meetings with the field assistants and community representatives. The consolidated findings were then reported back to all actively engaged project participants and finally evaluated and summarized at the project level by the authors.

The reflection process revealed manifold insights about the experiences and perceptions of the local researchers and field assistants, the strengths and weaknesses of the local research group approach, and of including action research and learning as a local development component in conventional academic-style research projects. This text is an attempt to compile the principal outcomes of this reflection process from the perspective of the locals who participated in the 
research groups. To emphasize this local perspective, we refrain from an academic presentation of the results. Instead, we compiled the text fragments and original statements of the local researchers into a single virtual journal written by a fictitious farmer who participated in one of the local research groups. This way of presenting the insights gained allowed us to abstract the many specific observations from the case studies and condense the diverse experiences and perceptions into a single, hopefully easily readable, story. However, although we have done our best to include and reflect the intentions and statements of local researchers whenever possible, it should not be forgotten that we, academics, wrote the text, and thus it naturally reflects our interpretation and evaluation of the discussion process. The text does not describe a specific case study, nor does it describe any single real person, but an idealized composite of what we observed and heard in the talks, interviews, group meetings, and field visits during the four years of the ForLive project and the final sequence of reflection meetings.

We present a virtual journal written by the fictitious farmer, Pedro Martinez, living in the also fictitious, small community, Nuevo Horizonte, located in the Amazon region of northern Bolivia. The journal expresses, in a greatly summarized way, how the farmer and his family may have viewed the project and the work of the local research group. We also created the character of the recently graduated Ing. Miguel as the project's first field assistant responsible for the facilitation of the group. ${ }^{1}$ He reflects, to a certain degree, the typical professional profile of some of our field assistants. The document accompanies the process from the first arrival of the field assistant in the community and how this is viewed by the residents. The series of meetings in Nuevo Horizonte follows the sequence of events proposed under the action research process involving several steps. The problems and perceptions of the community are presented through the eyes of Don Pedro, presenting his understanding of the process in the first place and as it evolved; the identification and selection of priority themes for local research and learning, and the formulation of research questions; the formation of the local research groups and their coordination; the planning and implementation of activities to answer the relevant questions; and the evaluation and reflection on the process and the subsequent cycles of planning, implementation, and reflection.

\section{Introduction by Pedro Martinez}

My name is Pedro Martinez, I am a farmer from the community of Nuevo Horizonte in the municipality of Puerto Rico located in the Pando, the northernmost department of Bolivia. I am aged 36 and was born and raised in the village, leaving occasionally to look for work with logging companies or on the nearby haciendas (cattle ranches). I left school at the age of 13 and went with my brother to look for gold on the River Beni. My father and mother live in Nuevo Horizonte. My father used to live in a barraca (a large rubber estate) tapping rubber trees for latex, but after the collapse of rubber prices, he 


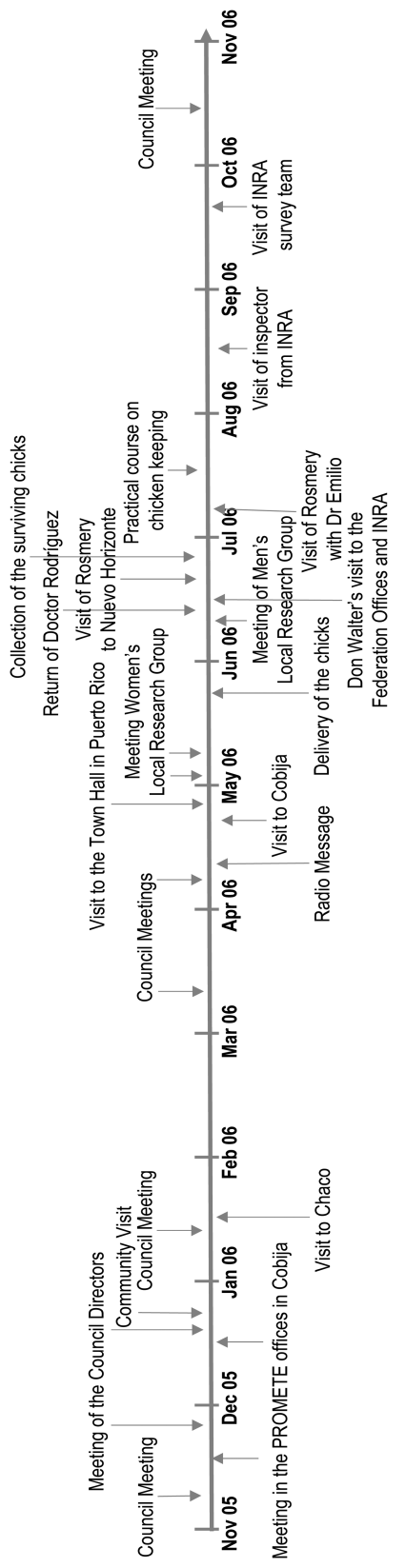


moved with the rest of the family to Nuevo Horizonte just before I was born. I met my wife, Maria, when I was working on a hacienda and came here to live when our first son was born. We have six children, Marco aged 19, Fernanda 18, Angelina 16, Julio 14, José 12, and Pedrito 5. We work on our 50-hectare plot of land, growing rice, maize, cassava, bananas, cocoa, mangoes, guava, and oranges. I own six cows. My wife has two pigs and 34 chickens. Every year, like my neighbours, I select an area of forest to clear for the chaco (crop land) to sow rice and maize, mainly for the family and the chickens, selling a little to get some ready cash. In December, I go to the forest to gather Brazil nuts, and from this, I earn enough money to buy the children's books and clothes for school with a little left over for the house.

Although I left school early, I can read and write reasonably well, and, for the past three years, I have been secretary of our community council and I am responsible for taking minutes of the meetings. Life for us has not changed much despite the promises from organizations that come and go, but something strange began to happen in our community three years ago. An NGO called PROMETE came to tell us about a different way of working that they called action research, something to do with a project called ForLive, or something like that. To be honest we didn't really understand anything at first. But little by little the young agronomist, Ing. Miguel slowly began to gain the trust of the community and explain a different way of working. Anyway, since I am the secretary of the council, I thought it would be of interest to you to share our experiences. This all began in our November meeting of the council in 2005 (Figure 2.1).

\section{The story}

\section{Council meeting on Sunday, 20th November 2005}

Today, we had our monthly meeting of the council to discuss the organization of community affairs and how to carry out the work to weed the football pitch. Just before the meeting started, three men turned up in a brand new Toyota pick-up. I thought to myself that they must be here from the timber company again, but when they got out of the vehicle one of the men looked familiar, and I had seen him in the village before; another was a well-dressed young man, and the third man was a Gringo. Towards the end of the meeting, the welldressed young man raised his hand, stood up, and asked if he could tell us about a new way of working in the community. He introduced himself as Ing. Miguel from the NGO "PROMETE" based in Cobija. The other man, Ing. Juan, was also from PROMETE and told us he had worked here before with the NGO CHOCLO on a project to improve farming practices in the community. The Gringo introduced himself as Simón, but I couldn't understand what else he said. Ing. Miguel told us about a project called ForLive; it was a new way of finding out information that would help our community to develop. He told us that he wanted to work with a family that would be a case study, he said something about our forests and also that we could decide what we wanted to 
find out, but I didn't understand what he was really getting at. Looking at the Gringo, Don Walter (our president) asked Ing. Miguel how much money they would bring to the community and told him that we need a machine to cut the grass for the football pitch and a new bridge on the access road into the community. Ing. Miguel didn't seem to pay much attention. Instead, he asked us all to stand in a circle holding hands and talk about problems in the community. I thought that that was a real fairy business. I saw Ing. Miguel taking some notes. God knows what for. He must have some weird ideas about our customs here. At the end of the meeting, he asked if they could come again to explain the work in more detail at our next meeting. Nobody in the village was paying much attention, but we agreed that we would discuss the matter among ourselves and send a message to the PROMETE offices in Cobija to let him know our decision. We had to hurry off after the meeting as the lorry was waiting for us to go to a football match in Villa Bella, a village five kilometres away, to play a key match in the local Sunday league.

\section{Meeting of the council directors on Thursday, 14th December}

A group of us met at the house of Don Walter in the evening to talk about the request of the people from PROMETE to meet with the community. We have always had institutions visiting and working with us in the past and we have a particularly good relationship with the church that has brought all sorts of benefits. Last year, the church brought us a water pump and tank. Other projects like the NGO CHOCLO have worked with us and given us plants and seeds. So, when we heard that PROMETE wanted to come to work with us as well, it did not take long to decide to accept their request to meet the following Saturday. Don Walter was very keen; he could only see benefits, especially as he knew that whenever a Gringo is involved in a project there is a lot more money involved. He had already started to make a list of the things that he thought would be of benefit to the community. So it was decided that as I had to go to Cobija on Friday to do some paperwork for the council, I would pass by the offices of PROMETE and inform Ing. Miguel that he would be welcome to come to our meeting on Saturday.

\section{Meeting: PROMETE offices in Cobija on Friday, 15th December}

On Friday morning I got up at three o'clock to start the journey. I had to walk for two hours to the main road as my bicycle had a puncture. As I sat by the roadside waiting for the bus to arrive, it started to rain. How I wished I had a Toyota pick-up like the technicians from PROMETE! At 7:30, just as I was beginning to think the bus would never come, it came around the corner bursting with people travelling from Puerto Rico to the market in Cobija. I managed to find a space to stand between two large women and their chickens.

On the journey to Cobija, I thought about the injustices of life. Here I was, travelling to Cobija on a hot and sticky bus, where I would have to stand for 
three hours surrounded by people and animals. The purpose of my visit was to meet with people who at the drop of a hat could get into an air-conditioned pick-up and ride out in comfort to our community. What was it that made it possible for these ingenieros to work in this way and why had I agreed to go to see them? Why could I not achieve as much if not more than them if I had the same conditions? After all, they seemed to know very little about agriculture or the conditions of our community and gave very little advice that was of any practical use. People who came from outside asked more questions and provided very few answers to the problems we faced. I began to wonder to myself if people coming from their comfortable homes in the towns were capable of understanding how we live and work in the forest? Are these people who come from such a very different world to us capable of understanding us and helping us to make a real difference in how we live? If they lived with us in the community for a week, I am sure they would learn more from us than in a year at the university. I also wondered if Ing. Miguel realized that we have so much to do. He seemed to think that we had time on our hands and could just stop work. He doesn't seem to realize how difficult it is to get the community to agree to act on a particular issue. Ing. Miguel seems to think that it can all be done so quickly. It is not like that at all in the community, we need time to discuss.

I arrived in Cobija and asked a friend I met there, Miguel Bustos, my wife's uncle, where I could find the PROMETE offices. He had a vague idea and pointed me in the general direction of a new suburb on the outskirts of town. I had come with just enough money for my bus fare, and for a bite to eat at lunch time so I had to walk to the offices, which I eventually found after wandering the streets for an hour or so. I knocked timidly at the door; the secretary seemed to ignore me although I knew she had seen me. Perhaps it was my dirty sandals or my old shirt that didn't create a good impression. Then, in the corner, I saw Ing. Miguel coming out of the bathroom. I called him over and he greeted me but didn't seem really to remember who I was or where I came from. I reminded him of our meeting last Sunday and told him that the council directors had met the previous evening and had decided that we would be glad to receive him at our meeting on Saturday so that he could tell us more about the benefits that he would bring to Nuevo Horizonte. He told me that he would be there at ten o'clock but had to rush off as it was nearly midday and had to collect his daughter from school. He jumped into his jeep and drove off in a hurry. I turned round to walk back to the centre to visit the Federation and find something to eat for lunch. When I finished my business in the Federation it was too late for lunch, so I walked back to the bus terminal to catch the five o'clock bus to Puerto Rico. By the time the bus reached my stop, it was dark. I arrived home at ten o'clock in the evening, tired and hungry.

\section{Council meeting on Saturday, 16th December}

Although I had not slept much, I woke up early as usual and went round to the house of Don Walter to tell him that Ing. Miguel would attend our meeting 
and that we should go and tell everyone to prepare. Between the two of us, we managed to visit every household in the village. At around nine o'clock it began to drizzle a bit and we gathered in the schoolroom to arrange the chairs for the meeting. By ten o'clock it was raining a bit harder. Because it was Saturday and the weather was not good for weeding the rice, nearly everyone from the community was there. We had finished our own agenda after an hour with Don Walter deciding what we would do to get the water pump repaired and how we would get the municipal government to repair the leaks in the school roof. There was still no sign of Ing. Miguel, so we waited for a while thinking that he would arrive any minute. At midday I was ravenous, and everybody was beginning to get restless and blame me saying that I had made a mistake and that Ing. Miguel would not come. I persuaded everyone to wait for a bit longer. By one o'clock most people had lost faith and had left to have lunch and even my wife began to tell me that we should go as the children were hungry and the youngest was beginning to cry. We waited for another half hour and decided that Ing. Miguel would not be coming, after all, so we went home to have lunch and then to do a bit of weeding although it was hardly worth it by this time.

\section{Community visit on Wednesday, 20th December}

Today was a beautiful sunny day so I got up early to go to the rice field to make the most of the good weather to finish off the weeding. At around 11 o'clock my eldest daughter, Fernanda, came out to the field. I thought it was early for her to bring me lunch, and since I had run out of coca, ${ }^{2}$ I was hungry and glad to see her. As she got closer, I saw that she had brought nothing with her for me to eat and she looked troubled. She told me that Ing. Miguel had arrived at the house, and he had sent for me to go to talk to him. I was really annoyed as I needed to finish weeding the crops and it was such good weather to work, but I thought again of the benefits that he would bring to the community and thought it better to go talk to him. Half an hour later I arrived at the house to find Ing. Miguel sitting at the table eating lunch. My wife is always very hospitable to visitors and especially people from the city. Ing. Miguel explained that he could not come on Saturday because of the rain but asked for another appointment at the next council meeting in January. I told him that I could not decide, but that it was the responsibility of Don Walter, the president of the council to decide. So, once he had finished his lunch, we went round to Don Walter's house. Don Walter was naturally delighted to think that Ing. Miguel would be able to meet with the community after all and told him that he could come to present his project at the next meeting to be held on Sunday 15th January. I then returned to the rice field to continue weeding during what little was left of the day.

\section{Council meeting on Sunday, 15th January 2006}

Although it had started to rain, I was now less worried. My rice and maize were weeded, and the other crops were doing well. I had not left the community 
this year to harvest Brazil nuts like many men because I thought I could get a bit of casual work repairing fences on the nearby hacienda. Because of the Brazil nut harvest, there were not many people at the meeting, and when the men are away the wives don't participate either. Besides Don Walter and myself, there were only eight people present altogether. This time Ing. Miguel arrived in time for the meeting accompanied only by the Gringo - just as well, as he was bound to be the person with the money. In his explanation, Ing. Miguel told us that ForLive researched how the forest in the community is of benefit to us and the way we live. He explained all the different benefits of the forest and how it could make us rich! It really made me wonder why I was so poor after listening to everything he said. He told us that there were different kinds of research: research that people like Don Simón, the Gringo would be doing that he called academic research, research that Ing. Miguel himself would be doing that was of general interest to the project, and research that we from the community would do that would be relevant to our daily needs. He told us that research was to create understanding and discover how to improve the way we live and work. In addition to the research, he also told us that they would be visiting the community to collaborate with us to resolve other problems. He called this the "collaborative agenda."

Ing. Miguel also asked us to choose a family from the community with which he would be able to work and also told us that it was important to sign an agreement with the project so that PROMETE would be able to work formally with the community. He finished his presentation explaining the steps of what he called "action research," telling us that we should meet to decide the themes that we want to research, and that women should form one group and men another group. In the steps, he told us that we had to plan activities, carry them out, and then think about what we had done and then plan again. All very confusing, and I wondered if we had already done the work why we should plan to do it again, but I didn't want to appear stupid, so I didn't ask Ing. Miguel to explain. Anyway, thinking of the benefits that all this would bring, we decided to do as he said and suggested that it would be better to organize this in March when the men come back from the Brazil nut harvest and when the rice and maize harvest were also finished. In the meantime, we would continue to think about what it was we would investigate. As there was nobody else at the meeting who was prepared to accept the responsibility of the case study, Don Walter said that I should be the person that Ing. Miguel could work with from the community. I was not too sure what this would mean but hoped that Ing. Miguel would not take up too much of my time. I also found the idea interesting as I am always keen to learn how to do things differently on my land and thought that Ing. Miguel would be able to help. Ing. Miguel told me that he would come the following week to visit me, but that we needed to organize a meeting with as many people as possible from the community to plan the action research activities. So we fixed the next meeting for Sunday 12th of March. In the meantime, Ing. Miguel said he would come to visit me in my chaco and talk with the family on the following Thursday. 


\section{Visit to chaco on Thursday, 26th January}

When Ing. Miguel arrived, I had already done four hours of work slashing back the weeds in the cows' pasture and stringing the barbed wire fences. He arrived all hot and sweating with my eldest boy, Marco, who had brought his machete to help me. Ing. Miguel asked me if I could take him on a walk around the farm to show him the main areas where I produced the crops. He wanted to see the areas of forest at the back of the farm where I have a few Brazil nut trees and where, on occasion, I fell a tree to make fence posts or to sell timber to buy some of the family essentials. It took us about two hours to walk around the farm and the forest. Ing. Miguel was full of questions that seemed really strange to me. He asked me the names of the trees and what they were used for. He seemed confused by the names of the plants and was a bit frightened of the cows when we went into the pasture. When we got back to the house, he was tired and could hardly talk. He asked my wife and children to help me draw a map of the farm to show where everything was and then to tell him what was produced where and if it was consumed on the farm or sold. He continued to ask questions and take notes at the same time. I wondered what it was he was writing and how he would use all this information. Ing. Miguel also had some suggestions, telling me that it was bad to burn and that there are other ways of farming without burning. I couldn't imagine how on earth he thought this might be possible and imagined that he would not survive for long as a farmer. He left with the map under his arm and promised to come back after Carnival.

\section{Council meeting on Sunday 12th March}

When Ing. Miguel came back for the meeting, this time he brought a young girl with him, she spoke with a strange accent. It turned out that she was called Marta and was from Mexico and she was studying how people use plants from the forest. Eventually, we summoned most of the people who were in the community at that time, and surprisingly, there was quite a lot of interest with 26 people turning up, between men and women. After we had finished our agenda, Ing. Miguel stood up to present the subject of action research and describe how he wanted to work with us, repeating the points that he had made in the previous meeting. This was useful because, to be honest, it was not at all clear what he expected, and nobody remembered or understood the complex diagram that he had presented. He divided the people up into two groups, one for the men and one for the women, and asked each group to draw up a list of the important issues. During the discussion, Ing. Miguel visited the groups to help guide discussion and provide ideas. I didn't really understand this as I thought we were supposed to give him ideas of what we should research and not him give us the ideas, but since he was in charge, I supposed he knew what he was doing.

After an hour or so of discussion, the men's group had a list of seven points, but nobody could agree on which of these was most important. The list was as follows: 
- Improvement of roads

- $\quad$ Rice mill for the community

- Control pests and diseases in cocoa

- Improve cattle production

- Demarcation of plots

- Control of fires

- Management plan for timber

So it was good that Ing. Miguel was there, as he was able to make suggestions about the need to control fire and having a management plan for the forest. I wasn't sure what a management plan was, but it sounded important. Also, I felt that if Ing. Miguel suggested it then it must be a good idea. Unfortunately, there were some members of the men's group who did not agree, so we could not make any firm decisions about what it was we wanted to do. The three biggest farmers who had more cows wanted to study the problem of cattle production, but those without cows were not at all interested. On the other hand, a group of farmers who had large cocoa plantations was keen to find out how to control pests and diseases in this crop, but this was of no interest to the cattle farmers. In the end, we decided to just present a list and not define until later what would be the theme of research.

The women's group had fewer problems in working together and quickly decided how they wanted to work. The key areas that they identified were:

- Control of diseases in chickens

- Improvement to the health post

- Reroofing the school

- Sewing machines for the mothers' group

I was elected by the men's group to present the result of the discussion and tell everyone why we had chosen the themes. It seemed obvious to me, with the roads in such a bad state why we should improve the roads. Also, with the rice mill to dehull and polish rice locally, we would be able to improve the price for the sale of rice and not depend on intermediaries who buy our rice at low prices. We also have terrible losses of our cocoa and don't really know why, although some people in the community have been on training courses. This is really worrying for some of us as the price of cocoa is pretty good, but we lose a lot just before the harvest. The three bigger cattle farmers told us of the problems they have as many calves suffer from diarrhoea and die, and this represents a big loss.

We also have a permanent problem in the community as nobody knows exactly the limits of their plots of land and there are many disputes caused by the sale of timber or harvest of Brazil nuts from neighbours' plots. Only last year my neighbour, Don Felipe, felled two Cedro ${ }^{3}$ trees in my forest, insisting that they were on his land. Also, over the past two years, we have suffered a lot from forest fires that have spread from pastures when burning has got out 
of control. Two members of the community have lost their houses and all of their belongings in fires. Ing. Miguel is convinced that all of our problems will be solved if we have a management plan for our forest, although we are not too sure what this is.

The women's group selected Doña Rosa, the wife of Don Walter, to present the results of the discussion of their group. She told us that the major concerns of the women were with the so-called pest that kills off flocks of chickens every now and again. Doña Rosa also told us that the women were worried about the state of the health post that was falling down and had no possibility of storing vaccines in a refrigerator due to the lack of electricity. The other great problem is with the school roof that leaks like a sieve, affecting the children's studies. The women also suggested that they needed sewing machines to make or mend clothes. I was glad to hear this last suggestion as I could really do with some new shirts.

Ing. Miguel told us that some of the themes we could do under action research and that others would be more suited to work in the collaborative agenda. For example, he said that we could study how to repair the roof of the school or construct a tree nursery (I couldn't remember that this had been mentioned by either group, but he seemed to think it was a good idea) as part of the collaborative agenda. It was then for the first time that he told us that action research was not about giving benefits to us, but that we had to go out and do the work ourselves and find out how to bring resources to the community. This caused much discussion, and some people began to lose interest at this point thinking that they had wasted all this time in the expectation that Ing. Miguel would bring resources to benefit the community. Ing. Miguel explained that there were some resources to use for action research but that it was to cover local costs such as travel and food but not much else. He asked both groups to consider our priorities and that he would come back in two weeks for another meeting. Because we did not have a meeting on our agenda in two weeks, we suggested to Ing. Miguel that it would be better if he could come during the week and stay overnight and have the meeting in the evening when nobody works. He did not seem to like the idea very much, but in the end, he agreed, so we set the meeting for Tuesday 4th April. It was agreed that Don Walter would inform those members of the community who had not attended the meeting of the importance of the next meeting in helping to decide the subjects that would be of most interest to the community. Marta, the girl from Mexico, asked if she could also come to work in the community and if it would be possible for her to stay with a family for a month to do her fieldwork. We felt sure that if Marta came to stay in the community, then Ing. Miguel would also want to visit more often. As they departed, two brothers, Jorge and Miguel Ibañez approached Ing. Miguel and asked him to bring grass seed for their new pastures that they were sowing.

\section{Council meeting on Tuesday, 4th April}

Ing. Miguel and Srta. Marta arrived just after lunch in the community and came to look for me in my rice field. Ing. Miguel continued to ask me questions and 
take loads of notes about what I said. He told me that it was for an information pack and that people from a university in Germany sent him messages the whole time to provide information for them to process. Marta seemed to manage well and talked most of the time with my wife and children when they were in the house. She even helped my wife with the cooking and taught her to make tortillas!

In the evening we met in the school. This time there was a good turnout, and there seemed to be more interest as rumours had run around the community that the NGO was going to build a new school and give plants away. This seemed to have raised a lot of expectations and people were really interested in what they could get out of PROMETE. At the beginning of the meeting, Don Walter explained what had happened to date and asked Ing. Miguel to describe the process again, and what it was that PROMETE was doing in the community and the different forms of work that were proposed. We finally got to talk about the collaborative agenda of the project that PROMETE was doing and the action research that was meant for our topics. Jorge Ibañez, reminded by this, asked Ing. Miguel if he had brought the seeds he had asked for. Ing. Miguel told him that he had forgotten but that he would bring them the next time he came. Jorge was really annoyed and accused him of only helping me and told him that he also wanted Ing. Miguel to visit him and tell him what to do on his farm. I tried to explain that this was not the case, but he would not listen, and in the end, walked out of the meeting in disgust. Ing. Miguel did not know what to say.

Eventually, we started the meeting talking about action research again. The two groups met separately again, and the women's group quickly decided that the subject they wanted to research was the cause of the deaths of their chickens and how to manage it. The men's group continued to have problems in deciding what to do. There was a heated discussion between those who grow cocoa and the three wealthier cattle farmers. In the end, both groups reluctantly decided that they thought that the problem of internal land disputes was of most relevance to the community. So it was agreed that this would be the issue to be researched. Key people from the newly formed groups were selected to be "local researchers," and we then met again to plan what it was that we were going to do.

The women's group decided to form a commission that would travel to Cobija to visit a local vet from the NGO ALITAS that Ing. Miguel told us helped with small animals. The women then sat down to think about how they would travel to Cobija and visit the vet. The commission was made up of three people, Doña Rosa, Sra. Miguela, and Sra. Jacinta. They drew up a plan to travel to Cobija by bus to visit ALITAS to consult the vet. Ing. Miguel said that as promised PROMETE would cover the travel costs. The women's group, with some help from Ing. Miguel, then calculated how much this would cost and presented their budget to everyone.

For the men, this was not quite so easy. They had many problems agreeing about the composition of their commission and who should be designated 
as the local researcher responsible for the coordination of the activities in the group. In the end, I was designated as a representative along with my cousin, Enrique Lopez, and his brother-in-law, Erick Cortez. Ing. Miguel came over to our group to help us design a plan, and also draw up a budget for a visit to the local office of INRA ${ }^{4}$ in Cobija.

Nobody in the community really had a clear idea about the collaborative agenda and how this was different from action research and, to be honest, it seemed that Ing. Miguel was not too sure either as he seemed to doubt at times what he was telling us. In any case, it didn't really matter much to us as long as we felt that we could obtain some benefit from the effort that we were putting in. We continued to talk about our agenda and how we would work together to organize a visit to the Mayor of Puerto Rico, our municipal capital, to get him to repair the roof of the school.

We planned to travel in two weeks in a joint commission made up of the representatives of the women's and men's groups to visit ALITAS and INRA respectively; then both groups would visit the Mayor of Puerto Rico on the way back to Nuevo Horizonte. The journey to Cobija was planned for Thursday 27th April with the visit to Puerto Rico taking place the following day, catching the evening bus back from Cobija to Puerto Rico where we would stay the night with relatives.

The community meeting ended at nearly midnight but oddly nobody complained, and we all felt very positive about the discussions and the way things were being planned; we were feeling as if we were really making decisions and defining what was best for our community. At the end of the day, we were deciding for ourselves. This had not happened before, and in the past, Don Walter or people from the municipality or the church had come and given us what they thought we needed according to their programmes and projects. My wife took Marta back to the house to sleep, and Ing. Miguel strung up his hammock in the school room to sleep there.

The next day we got up early as usual to prepare breakfast. Marta helped Maria to make some coffee and I went to see if Ing. Miguel was up and about. He was still fast asleep when I arrived at the school room. I woke him up and invited him round to the house for breakfast. Ing. Miguel was covered with mosquito bites and his face was quite red. But he had survived his first night out in the community. After breakfast, he and Marta wanted to visit the forest and take some samples of plants and asked me to accompany them to tell them the names and uses of the plants. We finished this task by lunchtime. He told us that he would send a message on the Radio Pan Amazonica to confirm our meetings before departing with Marta for Cobija. It seemed he didn't want to stay for lunch although my wife, Maria, had invited them.

\section{Radio message on Wednesday 19th April 2006}

As usual in the morning, before going out to the field, I was listening to the news and local announcements on the radio when I heard the message for 
Community Nuevo Horizonte telling us that the meetings were confirmed for the 27th of April and that we should travel to Cobija as planned. I hurried round to the houses of Enrique and Juan to tell them and also to tell Doña Rosa so that she should mobilize her commission as well. Ing. Miguel had not left any money to pay for the bus fare so between us we had to go round and ask our neighbours to lend us 12 bolivianos each. We planned to meet on the evening of the 26th of April to plan our questions and what we were going to say in our meetings as Ing. Miguel had asked us to do.

\section{Visit to Cobija on Thursday, $27^{\text {th }}$ April}

As I had done on the previous occasion when I travelled to Cobija, we left Nuevo Horizonte early to walk to the main road to catch the bus; the only person who stayed behind was Enrique who got cold feet about the journey. Although it was a mild morning we were in good spirits and full of hope that we were on the road to doing something that would make a difference in our community. When we arrived in Cobija it was still early, and we were all hungry from the walk but had no money to buy breakfast in the market, so we set off to walk slowly up to the offices of PROMETE. Luckily, we met Ing. Miguel in his pick-up coming down the road. He told us that he was coming to take us to the meetings, but that first he wanted to take us to the offices of PROMETE to reimburse our costs. He gave each of us 56 bolivianos (24 bolivianos for the return bus journey, three bolivianos for breakfast in Cobija, six bolivianos for lunch in Cobija, five bolivianos for supper in Puerto Rico, three bolivianos for breakfast in Puerto Rico, another six bolivianos for lunch, and finally nine bolivianos for the bus back to the turning to Nuevo Horizonte). We realized that we were not going to get rich on this project, but it meant that we could now go and get something to eat at the market before our meetings. Ing. Miguel took us back down to the market and we sat discussing what we were going to say at the meeting. Ing. Miguel took the women round to their meeting with the vet, and we waited for him to return to go to the meeting with INRA.

We arrived at the offices of INRA with Ing. Miguel who had returned having left the ladies in the offices of ALITAS. We were shown in somewhat reluctantly by the policeman at the door and asked to take a seat. There were only two chairs and three of us, including Ing. Miguel, so we stood waiting for the secretary to return to her desk. After about ten minutes she emerged from an office and sat down to answer her mobile phone without even saying good morning. After her call, she shuffled the papers around on her desk and looked up at us. Ing. Miguel spoke for us telling the secretary that he had made an appointment with the regional director of INRA for representatives of the community of Nuevo Horizonte to speak to him about a process of regularization of land titles and demarcation of land plots in the community. The secretary told Ing. Miguel that the director had not arrived but that he would be there in an hour or so. We had no option but to wait. Our high 
spirits fell, and we suddenly felt unimportant and ignored. Although we had heard about INRA, we had no idea about how it could work for us and what this implied. Anyway, after two hours of waiting the director arrived. The secretary asked us to go through to his office. The director spoke to us briefly and then called in a lawyer called Dr Hinojosa who would be able to tell us what we needed to do to sort out our land titles. The director then left for an important meeting. Dr Hinojosa told us that INRA was completing some land titling processes in the region, including neighbouring communities and that if we formalized a request, then Nuevo Horizonte could be included under the simplified titling procedure. He provided us with an example of a formal request and suggested that we should contact a nearby lawyer who advises the Federation of Campesinos (small-scale farmers) on the land titling procedure.

We left the offices of INRA to find the women's commission waiting outside for us. They had finished their meeting earlier and told us that the vet had suggested that the community of Nuevo Horizonte could be included in a project to provide technical assistance to communities in the region to improve small animal production. The vet, $\operatorname{Dr}^{5}$ Rodríguez, had said that he could visit the following Saturday, 6th May, to give a talk to the women's group and to tell them about the project. So, on an optimistic note, we went off to the market for lunch, leaving Ing. Miguel to go to pick up his children from school.

To make full use of our time, we decided to visit the lawyer of the Federation of Campesinos to ask him how we could formalize the request to be included in the process of land titling that INRA was carrying out in the region. Dr Suarez, the lawyer of the Federation, told us that he could do the necessary paperwork but that he would need Don Walter to come to visit him to sign the papers and provide copies of the necessary documents that proved the legal status of the Community Council and Don Walter as its legal representative. So far all seemed to be going well.

We left the Federation feeling that we had done a good day's work and walked over to the bus terminal in good time to catch the early evening bus to Puerto Rico where our relatives were waiting for us to stay. We waited for ages for the bus to arrive but there was no sign of it. In the end, it left two hours late arriving in Puerto Rico at ten o'clock at night. We had to wake up the relatives when we arrived to let us in. So we went to sleep again without having any supper.

\section{Visit to the town hall in Puerto Rico on Friday, 28th April}

When we woke up in the morning, the relatives told us that they had seen the mayor leaving on the road to Cobija in the afternoon. We had breakfast early and hurried round to the town hall to see if we could get an early appointment with him. It turned out that he was still in Cobija. Instead, we had a short meeting with the municipal coordinator, explaining the problem to him. We 
invited the mayor to come to visit Nuevo Horizonte to see the state of the school for himself. We felt that although we had not met him, we had made a first contact and we could go back to the town hall in the future. The meeting ended in time for us to walk round to the bus stop and catch the bus back to the road turning to Nuevo Horizonte. We arrived home in the late afternoon and went round to the house of Don Walter to inform him of the events.

\section{Meeting of the women's local research group on Saturday, 6th May}

The women had met on several occasions to discuss how to prepare for the meeting with Dr Rodríguez, and on one occasion Ing. Miguel had visited the group for a day to talk to them about how to present their problem and the research question that they had selected. The ladies felt well prepared and that they knew how they wanted to tell the visiting vet about their problems. So it was with great expectation that they awaited his visit. In fact, the visit had generated so many expectations that half the village had turned out to meet the vet, including most of the men from the community. At around ten o'clock, Dr Rodríguez arrived in his Suzuki jeep shortly followed by Ing. Miguel in his pick-up. We wondered why they had at least not come together in the same vehicle. The ladies were ready with their presentation and had invited Doña Rosa to do the initial presentation of the group and their project. Upon their arrival, Ing. Miguel and Dr Rodríguez were promptly greeted by Don Walter who led them to the schoolroom where the meeting was to take place. Don Walter gave a long introductory speech in which he said how pleased he was to have a visit from the vet, and he now hoped that the problems of those farmers who kept cattle in the community would, at last, be attended to by Dr Rodríguez. With his opening words, he then asked Dr Rodríguez to address the group. Dr Rodríguez opened a huge roll of papers that explained the origin of the domestic fowl, the feed, habitat, history, anatomy, and everything else you could possibly want to know about the humble chicken, except that is, what the women's group really wanted to know.

At the end of his talk of nearly two hours, Doña Rosa stood up to thank Dr Rodríguez and explained as briefly as she could, now somewhat upstaged by the illustrious visitor, the problems that the community had with the sudden death of their chickens for no apparent reason. Dr Rodríguez explained about Newcastle's disease, parasites, vitamins, and such like, but told the ladies that in short, their chickens were not worth bothering with and that he could bring them ten chickens per family of an improved breed that he was sure would do much better. Moreover, he told the ladies, his project with ALITAS could provide the chickens at a very low cost as these were subsidized by the International NGO Proyecto Pollito. The women's group was delighted to hear this news and accepted the offer, immediately forgetting completely about their original proposal and the project that they had thought about and prepared during the previous days. Dr Rodríguez told the women's group 
that he would talk to Ing. Miguel to make arrangements for the chickens and explained that the group would have to prepare new chicken runs, improve the diet with a ration based on soymeal, and also give them a ready supply of clean water every day. Ing. Miguel told Dr Rodríguez that he thought the costs of the project could be partially met by his project if Proyecto Pollito could cover the rest. So it was agreed that each of the nine members of the women's research group would receive ten-day-old chicks of this wonderful new breed with sufficient food to rear them for the first 30 days.

The meeting closed and Dr Rodríguez and Ing. Miguel agreed to make the necessary arrangements for the delivery of the chickens from their respective institutions in Cobija. Dr Rodríguez told the group that the chicks would be delivered before the end of the month if the necessary preparations had been made according to the list of instructions that he would leave with Ing. Miguel. With this, Don Walter took the doctor round to the house of his great friend, Miguel Pinto, the biggest cattle owner in the community who had quickly prepared a barbecue for lunch and got a crate of cold beer in honour of the vet's visit. Don Miguel then primed the doctor for guidance and after lunch took him round to his corral to get some advice on how to treat his cattle for the tick infestation that was particularly bad that year.

After the departure of the doctor, the women's group met briefly to discuss the plans and preparations that they would make for the arrival of the chicks. The plans that the vet had left were complicated and difficult to understand but they thought that with the help of Ing. Miguel they would be able to get by. They decided that they would need the help of the men to build their new sheds using Motacu $^{6}$ palm thatch. The real problem was the chicken wire that would cost 56 bolivianos per roll, more than the value of two adult chickens! The ladies decided to go back to talk to their husbands and return to meet later in the week to finalize arrangements.

\section{Meeting of the women's research group, Thursday, 11th May}

After an early supper on the evening of the 11 th of May, the nine women who had originally made up the local research group met to discuss the outcome of their discussions with their husbands to analyse who would be able to continue with the project of the improved chickens. All but two members of the group had found a way of mustering up the money for the wire and managed to get their husbands to agree to help build the henhouse and run. Although two women had opted not to continue because of the high cost of the investment, other women now wanted to join the group seeing that benefits might be obtained by joining. The group discussed the admission of further members but decided not to permit this as this may reduce the number of chicks that they would each receive. So it was decided that they would send a message to Ing. Miguel and Dr Rodríguez indicating the outcome of their discussions and asking that ten-day-old chicks should be sent out to seven members of the women's group. 


\section{Delivery of the chicks on Saturday, 27 May}

Over the following two weeks, the seven families worked to cut and prepare the palm leaves, cut timber for posts and beams, and find 56 bolivianos to buy a roll of chicken wire, borrowing money from friends and relatives, selling a couple of chickens or in one case, selling a pig. In our case, Maria had convinced me to sell a sack of our recently harvested rice to cover the cost of the chicken wire. I did this reluctantly because of the high cost but said nothing knowing that she was convinced by everything the vet had told them. I spent three days cutting poles, posts, and cutting and preparing palm leaves. I spent a further two days building the shed and chicken run. I hadn't counted on doing all this work but if it made my wife happy it was a good investment of my time.

It was now the great day and Dr Rodríguez had sent a message over the radio saying that he would be arriving with the chicks before midday on Saturday. The women were so anxious that, from seven o'clock onwards, they met at the entrance to the village to wait for Dr Rodríguez to arrive. Finally, at 10:30 his Suzuki came into view, this time together with Ing. Miguel. The expectation was enormous. Upon arrival, Dr Rodríguez unloaded the chicks, which were packed in seven neat little cardboard boxes each with ten chicks. He also brought seven $10 \mathrm{~kg}$ bags of the special chicken rearing concentrate. No grubs and worms for these special creatures! Dr Rodríguez visited the families one by one to release the chicks into their new quarters, giving each family a word of advice. On arrival at our shed, he was critical of the height of the roof and the orientation saying that it should have been sited to run from east to west and that the eaves were too high for chicks, which might catch a chill with the onset of the cold southerly winds at this time of year. We didn't feel too bad as he had criticized virtually every chicken shed that he had visited, which in one way or another did not fulfil the specifications that he had given. The combination of the complicated text and the inability of most of us to read very well was a recipe for misinterpretation, but we were happy with the outcome at least; certainly, the chicks didn't seem to mind too much and appeared to adapt well to their new surroundings. If it hadn't been for the presence of Marta in the community, we would have been at an utter loss in understanding the instructions. Before leaving, Dr Rodríguez told us that he would return in two weeks to see what progress the chicks were making.

\section{Meeting of men's local research group on Wednesday, 7 June}

Events had caught up with the men's local research group and ever since the visit to Cobija they had not met formally except for the report of the visit that was presented to Don Walter. The success of the women's group spurred the men's group into action and stimulated them into meeting again to assess how they might advance in their mission to sort out the community's land titles 
and put an end, once and for all, to the internal disputes over the boundaries between the plots of land. Don Walter had not had time to go back to visit the Federation lawyer to sign the formal request to submit to INRA and start to do the work on the community titling process. We agreed to each pay two bolivianos to cover the cost of Don Walter's visit in the hope that all the community members would eventually support the work. So it was planned that on the following Wednesday, Don Walter would travel to Cobija to look for Ing. Miguel in the offices of PROMETE, visit the Federation lawyer to fill in and sign the necessary forms, and then go round to the INRA offices to formally submit the application as indicated by the INRA lawyer, Dr Hinojosa. The need to establish some contact with the Mayor of Puerto Rico was mentioned but no action was defined.

\section{Return of Dr Rodríguez on Saturday, 10 June}

By the time Dr Rodríguez was due to return to Nuevo Horizonte the spirits of the women's group had changed somewhat. Early expectations and hope had given way to concern and in one case despair as time went by. We had been lucky and only one chick of our ten had died. Doña Rosa had lost all but three of her chicks but did not know why they had died. She imagined that they needed a mother hen to keep them warm and that the charcoal embers burning in a tin were a poor substitute. Doña Jacinta had lost all of her chicks to a Carachupa (a predatory opossum) while Doña Juana had lost one to a Chuubi (a hawk), and three had been eaten by her neighbour's cat. When faced with this harsh reality, Dr Rodríguez appeared to be indifferent to the tragedy that this represented to most of my wife's colleagues, and instead suggested that he could provide 30 replacement chicks to be shared among the unfortunate ladies and recommended that more care should be taken by ensuring that the chicken wire was properly closed off, and if necessary, more should be bought to prevent animals from entering. In addition, he suggested that all of the chicks should be given antibiotics in their water and that the group could buy a flask of antibiotics costing 100 bolivianos and that this would be sufficient for all seven lots. So much had been invested so far it seemed a waste to give up now, so the group decided to accept the suggestion of Dr Rodríguez, and buy the antibiotics to give to the chicks. Dr Rodríguez said he would send the chicks out with Ing. Miguel on his next visit the following week and would visit the community again at the end of June.

\section{Don Walter's visit to the Federation Offices and INRA in Cobija on Wednesday, 14 June}

On the evening of the 13th of June, there was a knock on the door late, at around nine o'clock. I was tired from my day's work in the chaco planting 
cassava and with the cold south wind, I had decided to go to bed early. It was Don Walter at the door asking me to accompany him on his visit to Cobija the following day. He told me he could cover the cost of my ticket from council funds but that he needed me to go with him as I already knew the man from INRA and the offices of PROMETE. Although I had a lot of weeding to do, Don Walter convinced me to go with him. So, before going back to bed I cleaned my sandals and prepared my best clothes for the trip.

Don Walter and I got into Cobija around 9:30. We were both cold and tired as the wind had got up in the night and was now blowing hard. We went round to the offices of PROMETE to find Ing. Miguel, but to our great surprise, we were told that he no longer worked there and had taken a new job with the Superintendencia Forestal in San Borja. This was devastating news as we were beginning to get used to Ing. Miguel and understand the complicated words that he used, and at the same time, it seemed that he was also beginning to understand a little about the way we work and think in the community. The secretary told us that a new person had been designated to work with us, her name was Ing. Rosmery. The secretary called the director of PROMETE, Ing. Marcial, a very important man we guessed who came out to greet us. We explained the purpose of our visit to Cobija and the importance of our visit to INRA. He seemed to be aware of what we were doing. He told us that he was very interested in our work and had talked a lot to Ing. Miguel about ForLive and the importance of the work to PROMETE. Ing. Marcial told us that Ing. Miguel had left feeling uncomfortable about his role in the work in Nuevo Horizonte but that, upon reflection, he had learned a lot from the community and about his own role in working with groups of small farmers. Ing. Marcial showed us a note that Ing. Miguel had written, explaining the reasons for his departure and his suggestions as to how the work might be taken forwards in the future. Ing. Miguel had also commented in the note that he now recognized the value of farmers' own knowledge and experience and that the most important aspect of his work had been to enable families to come together to discuss common concerns and their solutions. Ing. Marcial seemed to be quite moved by the note and told us that the lessons shared by Ing. Miguel within PROMETE had influenced his decision in the selection of his replacement to work in Nuevo Horizonte. At this point, he told us that Ing. Rosmery would be working with us from now on due to the departure of Ing. Miguel at short notice. He called Ing. Rosmery to come to meet us and asked her to accompany us on our visit to INRA.

I was very sceptical that a young girl like Ing. Rosmery would be able to work with us in the community. How could she possibly know anything about our farming practices, how we live, and the reality of the rural communities in this area of the Bolivian Amazon? How I wished that Ing. Miguel, for all his defects, could return to accompany us and tell us how we should do our work. As we walked down the road, Ing. Rosmery started to ask a lot of questions, just like Ing. Miguel had at the beginning. It appeared that Don Walter was thinking the same as I was and told her that we had 
answered these questions before, and asked her if she had not read the reports that Ing. Miguel had written from all the notes that he took from his visits to Nuevo Horizonte. Ing. Rosmery told us that she had not received any notes or reports from Ing. Miguel and that one of the problems that he had in PROMETE was that he had not written anything down about his work or the process in Nuevo Horizonte. She told us that the project coordination had written a strong letter asking him to send the missing information by the end of June. As we walked on to the Federation I began to wonder if it was really worth all the time and effort that we had invested in the project and if, at the end of the day, it would bring any benefit to the community or if it might not be yet another project that would waste our time and come with false promises?

In the Federation, we were welcomed warmly by the General Secretary, who turned out to be some distant relative of Don Walter's. Somehow, he also knew Ing. Rosmery, which surprised me. After a few minutes, he called Dr Suarez, the Federations lawyer, to come to meet us and inform us what it was that Don Walter had to fill in and sign. Within half an hour we had completed the forms and taken photocopies of the relevant documents including the identity card of Don Walter and the minutes of the meetings at which Don Walter was confirmed as president of the community. In order to facilitate the process, Dr Suarez offered to go round to INRA together with us where he said he had some "contacts" who would help with the paperwork.

On arrival in the INRA offices, we got quite a different reception from the last time. On seeing that the Federation lawyer was with us, as well as Ing. Rosmery, we were invited to wait to see Dr Hinojosa and offered coffee and water! When Dr Hinojosa arrived, he greeted us cordially, paying special attention to Dr Suarez. Don Walter explained the motive of our visit. Dr Hinojosa informed us that as chance would have it at that moment, INRA had a team of topographers working in the field with the communities slightly further to the south of Nuevo Horizonte. He examined our forms and asked Don Walter to put his thumbprint on the bottom of each of the documents. He told us that all was in order and that if all went to plan and the regional director approved the process, then the topographers would be arriving before the end of September, before the end of the dry season. Dr Hinojosa asked us to return towards the end of July and suggested that in the meantime we could assist the work by cleaning the borders between neighbouring plots, especially where land disputes between neighbours existed.

\section{Visit of Ing. Rosmery to Nuevo Horizonte, Thursday, 22 June}

I had been out in the fields since dawn to harvest some cassava and came back early to have breakfast together with the family when to my surprise, I saw 'Ing. Rosmery' walking across the football pitch carrying a pile of books coming towards the house. I thought immediately that the Ingeniera does not know how to drive and has got stuck or had a puncture. As she got closer, I realized 
that the books that she was carrying were not books at all, but three boxes of chicks that the doctor had sent to replace the ones that had died. She came over and put the chicks down on a bench and produced a flask of new antibiotics recommended by the doctor from her pocket. She told us that this was to be paid for from ForLive project resources, which was a huge relief, especially now as the women's group had severe doubts about these new chickens. Some of the women began to question what had happened to the chicks' mother, and surely the mother hen had died and the vet now wanted to send the chicks out to them. They could not imagine that so many chicks could hatch and have no mother. We asked Ing. Rosmery how she had got to the village, and she told us she had caught the early morning bus to Puerto Rico and then walked in from the road. We somehow found this hard to believe. This was not the way for a real professional to behave!

Unfortunately, by the time of Ing. Rosmery's visit, the situation of the chicks had deteriorated even further. Of the 90 chicks that had been sent out, there were now only 20 survivors and six of these belonged to my wife, Maria. Our last hope lay in this flask of antibiotics that the vet had sent out to us, but, to be honest, nobody believed that this would make much difference. To make matters worse, the special chick-rearing feed that he had provided had just finished and no more had been sent. We managed to keep our chicks alive by breaking open termite mounds and feeding the grubs to the chicks, but they hardly seemed to know what to do with them, unlike our chickens that were used to this delicacy.

Ing. Rosmery talked with Maria for a while, and then they decided to go round to the house of Don Walter and Doña Rosa to discuss the situation of the chicks. It turned out that Ing. Rosmery had been brought up in one of the neighbouring communities and had then gone to study, so she understood everything we told her, and we also found that she had a simple way of expressing herself that really made communication much easier. She told us that she had heard that other communities had similar problems to our own and that the best way to start to improve the chicken production had been to vaccinate the chickens and to improve their diet. She said that it would be better to have a meeting with the rest of the group to discuss what had happened and to try to plan a way forward. There and then Doña Rosa and Maria decided to go out and summon the members of the group to a meeting.

Although the school room was unoccupied, the women's group decided to meet under the mango tree by the health post. Maria told me that they thought back about the process of planning and remembered that what they really wanted to do was to improve the way they kept the chickens that they already had and that it was not their idea to bring these wretched chicks to the village, but the idea of the vet who had convinced them that this was the best thing to do. They told Ing. Rosmery how they had borrowed money to buy the wire netting for the hen run and all the effort that had gone into building the sheds. Ing. Rosmery suggested that they might think again about the chicks and perhaps use the sheds for the chickens that they already had, and she could return 
the chicks to the doctor if that was what they wanted to do. Ing. Rosmery also told the women that she knew of a vet who was very good with traditional chicken breeds, and she could speak to him to see if he could visit the community to listen to the women and to see what suggestions he could make to improve the production of the chickens. This, the women said, was what they had intended to do in the first place, but Dr Rodríguez had convinced them to rear these useless chicks and made them forget what it was that they really wanted to do. Ing. Rosmery told the group that she would be accompanying the project until it ended and would attempt to facilitate the group to enable them to do what they wanted and strengthen their organization. The women's group asked Ing. Rosmery to see if she could organize the visit of this other vet and asked her to arrange for Dr Rodríguez to collect the chicks to take them back to Cobija.

By the time the meeting ended it was just about 11 o'clock and getting on for lunch time. Maria invited Ing. Rosmery to stay for lunch. Obviously relieved, she accepted the invitation and produced some rice and a piece of charque $^{8}$ from her backpack as a contribution to the lunch. Then both set about preparing lunch. Ing. Rosmery told Maria that she intended to stay the night in the schoolroom and go back on Saturday to carry out field visits to gather some of the missing data. Maria invited her to stay in the house, and the two of them carried on chatting. We quickly began to feel like Ing. Rosmery was part of our household and community and became accepted and recognized, especially by the members of the women's research group. The men's group, however, found it difficult to listen to her and to think that a young professional, particularly a girl, could really understand how their farms functioned and how she could be useful to them. Time passed quickly, and it was soon Saturday. To be honest, I was quite glad because with Ing. Rosmery's visit I had already missed two of the first round football matches of the World Cup on the radio, and on Sunday afternoon I was determined to cycle to the neighbouring village, Bella Vista, which has a generator and satellite dish to watch the game between Argentina and Mexico. What with the cassava harvest and the World Cup, there wasn't much time left for action research.

\section{Collection of the surviving chicks on Tuesday, 27 June}

We were surprised when just before lunchtime, Dr Rodríguez arrived in his Suzuki jeep to pick up the few surviving chicks to take them back to Cobija, where no doubt they would die. He seemed indignant that we should reject his wonderful offer and said very little. Upon giving him the 25 survivors that Ing. Rosmery had brought last week, Doña Rosa told him that she wished she had never heard of his supposedly wonderful chicks that had cost them so much money and made them buy so many items that they could ill afford, and which did not respond at all to the local conditions. After thinking for a while Dr Rodríguez said that it was their fault that the chicks had died as they did not know how to look after them and if they had done as he had said then 
they would have been fine. It seems that the vet could not understand what we were trying to tell him.

\section{Visit of Ing. Rosmery with Dr Emilio, 5 July; council meeting}

Early in the morning, I heard the sound of an approaching motorbike. I could not think who it might be until who should come round the corner but Ing. Rosmery bringing somebody as the pillion passenger. She pulled up to the house and presented Dr Emilio Choque, the vet she had told us about on her last visit. I really hoped that the visit would not take long as it was the day of the second semi-final of the World Cup, and I didn't want to miss it. I had got my bicycle specially repaired to go to see the game. Fortunately, Dr Choque was also keen to get back to Cobija to watch the match and wanted to have a quick meeting with the women's local research group to discuss possible collaboration. They went round to Doña Rosa's house and quickly organized a meeting of the group. Doña Rosa explained their research project to improve the production of their local chickens, and especially how to reduce loss from diseases that ravage the flocks every now and again. Dr Choque explained how they could use the infrastructure in which they had invested and how by improving the nutrition of the local chickens they could improve their productivity. He also explained how, by vaccinating, it would be possible to reduce losses from disease. He agreed to return to give a course on the subject in the middle of July. With that Ing. Rosmery and Dr Emilio hopped back onto their motorbike and drove off just in time for me to cycle off to see the Portugal versus France match.

\section{Practical course on chicken keeping with Dr Emilio on Wednesday, 19 July}

Just as he had promised, Dr Emilio returned to give a practical course to the women's group on chicken keeping. Instead of everyone sitting in the school room, they went first to see the chickens running around the houses. There were several men participating who were as keen to learn as the women. Dr Emilio pointed out some of the characteristics of more productive animals so that the women could learn to select these. He also very dexterously caught two hens and showed how to detect symptoms of illness and especially diarrhoea and how to distinguish between infectious diarrhoea and what he called physiological diarrhoea provoked at the onset of laying. When we went to see the hen runs, he was quite enthusiastic about the possibility of using these to improve the management of the chickens and especially their health care and nutrition. He then asked to be taken to a typical farm to see the plants being produced to see which of these would be appropriate for use in chicken feed. He showed us the cassava leaves, pigeon pea, maize, cassava peelings, kudzu, and a range of other products that we did not know were useful for chickens. In this way, by walking round the houses and chaco we were all able to learn and see that this was applicable to the conditions in which we live. At the end 
of the course, we returned to the house of Doña Rosa where we carried out a practical exercise of capturing ten chickens and one cockerel to be enclosed and kept under "improved management," in a way that the women could readily manage and copy if they wished to do so.

\section{Visit of an inspector from INRA on Tuesday, 22 August}

Throughout this period, Ing. Rosmery visited Nuevo Horizonte on a regular basis often staying the night and on various occasions staying for several days running, especially over the weekend, which she seemed to enjoy. Whenever she gathered data, she explained what it was for and how it would be used by those people organizing the research. Dr Emilio also came on a regular basis to visit the women's group and their chickens. He taught them how to vaccinate, select, and cull animals as well as the importance of providing good chicken feed.

During this time, the men's group remained relatively inactive as if they were waiting for something to happen before mobilizing themselves to act. Eventually, though, something did happen. Towards the end of August, a site inspector from INRA arrived in the community asking to see Don Walter and to make a few on the spot site inspections to quantify the amount of work involved in surveying the community and drawing up plans. With one matter or another, we had not organized the workgroups to clear the limits between plots. The inspector said that this was urgent if we were to receive the surveyors in the next three weeks as planned. Unfortunately, with the advent of the rains, we had been totally absorbed with the work of preparing the land to sow rice and maize and selling timber. We also had number of emergencies with the need to rush to put out fires that sprung up all around the community. We organized a meeting of the men's group later that same day and managed to stir up enough interest to organize workgroups to clear strips in the undergrowth of the forest between the plots of land. We drew up a work plan to show who was in which group and where they should be working so that all the parcels would be taken into account. The main stimulus to working in this way was the organization demonstrated by the women's group.

\section{Visit of INRA survey team on Tuesday, 26 September}

With the support and encouragement provided by Ing. Rosmery and the accompaniment of the work plan, it proved to be possible to clear all the old plot boundaries and discover some of the old boundary posts. The survey team was happy to be able to work in this way, and some of the young men from the village even learned how to use the GPS. The young overseas researcher, Simón, who had been away working in Brazil, was especially helpful with this task. By the end of the week, the community had agreed on the draft plans and divisions marked on the ground so that the intention now was to draw up a legal document called a land-use plan at the community level. 


\section{Council meeting on Sunday, 14 October}

Ing. Rosmery had asked the community if she could participate in the council meeting of October to be able to reflect on the experience to date of the action research and to draw on some of the lessons learned from the process. The women's group stressed the importance of defining their own agenda and sticking to it, saying that the experience for them had been very valuable. Together they had learned and been able to share their knowledge and experience, thereby enabling them to improve the productivity of their chickens and improve the nutrition for their children. They now felt that they were able to take on more challenging projects and that their organization had been strengthened by the process. Those women who had not participated directly in the process felt that although they had not been directly involved, the knowledge remained in the community. They felt that they would be able to consult with their fellow colleagues on how to go about improving their production and that together they had benefited from the improved organization. They recognized the role of the facilitator and had learned a lot about how they themselves can help and facilitate their own activities if they decide to do so.

The men's group, on the other hand, was more self-critical. They reflected on the fact that they had not been very active in the process and had suffered from a lack of understanding as to the purpose of action research and how it would affect them and their organization. They could see the benefit now that the issue of land titles was being resolved and were keen to continue to explore new areas of action related to production. Both groups found that the process had strengthened their organization and that they were now less dependent on external assistance. Ing. Rosmery thanked them for the generosity of the families and for having been so patient with her during the time she had spent in the community. Although this moment represented the end of the current phase of support to the community, she would remain working in the area and continue to visit the community on a regular basis.

Don Walter closed the meeting by announcing the forthcoming visit of the mayor to inspect the school for the repair to the roof and also repair and equip the classroom and promote a series of classes on adult literacy in the community. This would be the first time the mayor had visited the community in 12 years!

\section{Conclusions}

The short story reflects the big challenges that collaborative research, such as the work with local research groups, mean to both the local researchers and facilitating field assistants. To translate well-grounded theoretical underpinnings and elaborated methodological guidelines on collaborative research into practice is not so easy. Neither technicians and researchers nor local resource users come prepared to collaborate in this way. Still, schools and universities 
educate people to penetrate the socio-environmental realities and to implement expert solutions but not to enter into a dialogue with local resource users grounded in mutual respect. And the local research users are constrained by traditionally paternalistic structures that have created dependency and expectations on outsiders, marginalizing their own cultures and capacities to find solutions.

Of course, it could be argued that many of the mistakes reported in the story could have been avoided. But one should be aware that it is very likely that initiatives for collaborative research will be confronted with the same ingredients that initially severely limit the possibilities. The fact that we have observed many of the above-outlined difficulties in almost all case studies in similar ways confirms this observation, despite different institutional and socio-environmental settings, and most importantly, the involvement of very different people, locals as well as field assistants.

Challenges are manifold. First, they include difficult working conditions often related to long and costly travel and poor lines of communication. Then there is the expectation of communities that desperately wait for concrete, immediate help from outsiders approaching them with generous promises. Under the often very difficult conditions in which these communities live, they need their efforts above all to be dedicated to meeting their subsistence needs and the livelihoods of their families; they can only devote limited energy to time-consuming and longer-term solutions. Nor should we forget the lack of experience and willingness for collective work of many families, as well as (quite-justified) scepticism towards project staff, who often have little time and lead a privileged and secure life elsewhere. Another critical issue is the necessity to work with not always optimally selected and sufficiently trained field assistants. This includes experienced employees from NGOs and governmental agencies who were trained to effectively implement technical and organizational solutions following the mission and expertise of their host organizations. For most of these professionals, particularly foresters, environmentalists, and agronomists, it is difficult to shed the habits acquired over the years of "knowing" the solution to problems and showing others what to do. Often, it is the young but inexperienced professionals that are confronted with strong (often even mistaken) expectations from both sides, the programme coordinators, and the locals. These often enthusiastic, young professionals might be able to interact empathically with the locals but may suffer from difficulties translating this into concrete action on the ground. More concerning and not uncommon, external professionals often arrive with their own agendas such as the implementation of solutions pushed by their organization, or, in the case of young researchers, the need to gather data and write their theses. This brings a hidden agenda into play that introduces biases through subliminal messages and coding, which can manipulate the outcomes of participatory processes. The fact that almost all the local research groups prioritized topics that largely corresponded to the qualification and interest of the accompanying field assistant shows the great influence of the facilitating professional on the "locally defined 
agendas." Too often, we observed that the facilitators focussed on their agendas and difficulties and were largely unable to imagine the effort that cooperative working arrangements entail for the community members.

Also, we should not forget the wise seniors and bosses who manage these international research and development projects but, due to their duties, seldom have the time for extended fieldwork or intensive supervision. And, last but not least, we should be aware of the normally short time horizons of such projects and related funding, which often allow the initiation of local processes but not the necessary long-term support needed to generate ambitious outcomes.

Nevertheless, the story, as well as our experience from all the 17 in-depth case studies in the ForLive project, also indicates the enormous potential of collaborative approaches, despite all the challenges and drawbacks. Most importantly, collaborative working approaches, grounded in local action, force people to interact and talk to each other in the rhythm of rural realities. This creates understanding of the realities and capacities of others and allows for respectful forms of communication. Nearly every single local engaged in the initiatives reported that they had strongly benefited. They learned about the capacities but also of the problems of others, their specific ways to see reality; the collaborative process created space for mutual learning and discussions on perspectives, experiences, and knowledge. It is also clear that this research component built local learning and research capacity, generated interesting information for the smallholders, and stimulated the creativity and adaptiveness of the local resource users to problem-solving in their difficult contexts. In many of the case studies, this has contributed to a process of empowerment, collective action, and social organization. Also, as a result of the experience, the project's field assistants, be they NGO workers or young researchers involved in the project, expressed their willingness to continue working with an attitude of respect for local resource users and with a healthy scepticism towards quick solutions that are imposed from outside without taking into account local interests and capacities. However, it should be noted that these benefits accrued principally to those who participated more actively in the local initiatives. As always, learning remains confined to the hands of those who were actively involved in the generation of the lessons!

The manifold experiences in the ForLive project confirm the immense potential of collaborative working approaches, but they also indicate the need to carefully take into account the capacities and agendas of all actors involved, the researchers, technicians, their supervisors, and local research partners. It is important to be realistic in the setting of objectives, understanding local capacities, conditions, and timeframes. It is also clear that collaboration requires more than the simple application of participatory techniques and methods. It requires a true interest in and understanding of the perceptions and susceptibilities of the community and the inequalities related to logistics, lifestyles, and priorities. Adequate training and intensive supervision are mandatory but may sometimes be insufficient to overcome confirmed prejudices and working routines. 


\section{James Johnson and Benno Pokorny}

Most strikingly, despite all the enthusiasm about working in partnership with local resource users, it is important not to forget that, in the end, the only long-term commitment to the communities lies within the communities themselves. Supporting organizations, development professionals, and researchers come and go. Thus, building and strengthening the capacity of the families and communities to develop their own projects and facilitate their own processes might be the most important tasks for external actors.

\section{Notes}

1 Professional agricultural technicians receive the university title of ingeniero agronomo, which is abbreviated to Ing.

2 Farmers often chew coca leaves as a mild stimulant to offset the sense of tiredness and hunger. Coca is also chewed at meetings, and the exchange of coca is an important means of strengthening relationships of trust.

3 In Bolivia, Cedro includes a number of species that belong to the genus Cedrela spp. The species in the Bolivian Amazon region is Credrela odorata.

4 In Bolivia, the National Institute of Agrarian Reform (Instituto Nacional de Reforma Agraria) is responsible for defining land rights and granting of titles.

5 Vets are given the title of "doctor" in rural areas in Bolivia. Professionals tend to be referred to by the title as a term of respect.

6 Attalea phalerata, a palm tree.

7 The Bolivian Forest Service.

8 Dry salted beef.

\section{References}

Pokorny, B. 2013. Smallholders, Forest Management and Rural Development in the Amazon, 212p. Oxford, UK: Earthscan Forest Library/Routledge.

Pokorny, B., G. Cayres, and W. Nunes. 2005. "Participatory Extension as a Basis for the Work of Rural Extension Services in the Amazon." Agriculture and Human Values 22 (4):435-450. 